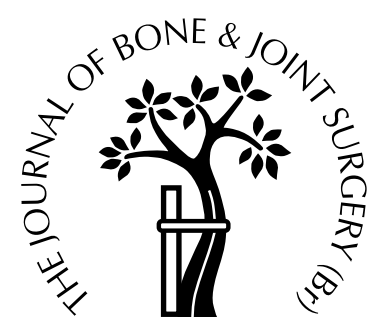

\title{
Hospital versus home management of children with buckle fractures of the distal radius
}

\author{
A PROSPECTIVE, RANDOMISED TRIAL
}

S. Symons, M. Rowsell, B. Bhowal, J. J. Dias

From Leicester Royal Infirmary, England

O ur aim was to determine whether children with buckle fractures of the distal radius could be managed at home after initial hospital treatment. There were 87 patients in the trial: 40 had their short-arm backslab removed at home three weeks after the initial injury, and $\mathbf{4 7}$ followed normal practice by attending the fracture clinic after three weeks for removal of the backslab.

Clinical examination six weeks after the injury showed no significant difference in deformity of the wrist, tenderness, range of movement and satisfaction between the two groups. Fourteen $(33 \%)$ of the hospital group compared with five $(14 \%)(p=0.04)$ of those managed in the community stated that they had problems with the care of their child's fracture. It was found that both groups, given a choice, would prefer to remove their child's backslab at home $(p<0.001)$. Our findings show that it is clinically safe to manage children with buckle fractures within the community.

J Bone Joint Surg [Br] 2001;83-B:556-60.

Received 27 March 2000; Accepted after revision 4 July 2000

The inherent stability of many fractures of the distal radius has encouraged the use of various methods of management. A recent report ${ }^{1}$ audited the treatment of greenstick fractures of the distal radius using a soft cast which was removed by patients at home. This showed effective reduction in the numbers attending the clinic and that the patients involved were satisfied with the treatment. However, without formal follow-up, the clinical effectiveness of such treatment remains in doubt. Our study aimed to show that

S. Symons, MB BS, MRCS, Senior House Officer

M. Rowsell, MB BS, MRCS, Senior House Officer

B. Bhowal, FRCS Ed (Orth), Consultant Orthopaedic Surgeon

J. J. Dias, MD, Consultant Orthopaedic Surgeon

Department of Trauma and Orthopaedics, Leicester Royal Infirmary, Infirmary Square, Leicester LE1 5WW, UK.

Correspondence should be sent to Mr J. J. Dias at the Department of Orthopaedic Surgery, Glenfield Hospital, Groby Road, Leicester LE3 9QP, UK.

(C2001 British Editorial Society of Bone and Joint Surgery 0301-620X/01/411211\$2.00 home management of buckle fractures of the distal radius is clinically safe and satisfactory.

\section{Patients and Methods}

The study was approved by the local Ethics Committee. Between September 1997 and May 1998, 154 children were diagnosed as having buckle fractures of the distal radius on presentation to the Accident and Emergency Department of Leicester Royal Infirmary. Of these, 101 were referred to the study team. We excluded patients who had pathological fractures, previous problems with the wrist on the side of the fracture, bicortical fractures and those who did not understand or were unwilling to enter the study. Patients and their parents were seen on the day of presentation. Three were diagnosed as having bicortical fractures, one had had previous abnormality of the wrist on the side of the fracture, four attended without their parents, one spoke no English, two wished to be followed up in another city and in three the parents refused consent.

This left 87 patients for whom parental consent for entry into the trial was obtained. These were subsequently randomised either to home (study) or hospital (control) groups using a computer-generated random-number sheet. In each group the fracture was treated in a below-elbow backslab. Patients in the hospital group followed our usual management for buckle fractures of the distal radius; they returned to the fracture clinic three weeks after injury for removal of the backslab by nursing staff and for medical review.

Those randomised to the home group did not return to the hospital, but had their backslab removed by their parents on a given date three weeks after the injury. Consideration was given to the ease and safety of removal of the backslab by parents at home. In order to avoid any possible injury to the child from the inexpert use of scissors, these patients had their backslabs applied, dried and cut but not removed, and then rewrapped with a bandage by the nursing staff at their initial presentation. This procedure was watched by the attending parent and a clear explanation of removal of the backslabs was given before they left the hospital. Parents of patients in the home group were given full access to the fracture clinic during the study period. It was emphasised that they should return to the 
Table I. Details of the home and control (hospital) groups and regional data by number and percentage

\begin{tabular}{|c|c|c|c|c|}
\hline & Home group* & $\begin{array}{l}\text { Hospital } \\
\text { group* }\end{array}$ & $\begin{array}{l}\text { East } \\
\text { Midlands }\end{array}$ & UK \\
\hline Mean age in years $(\mathrm{SD})$ & $9.4(3.6)$ & $9.1(3.3)$ & & \\
\hline \multicolumn{5}{|l|}{ Sex } \\
\hline Male & $23(61)$ & $24(57)$ & & \\
\hline Female & $15(39)$ & $18(43)$ & & \\
\hline \multicolumn{5}{|l|}{ Class } \\
\hline I Professional occupation & $1(3)$ & $2(5)$ & 4 & 5 \\
\hline II Managerial and technical & $9(24)$ & $10(24)$ & 24 & 25 \\
\hline III Skilled occupation & $18(47)$ & $22(52)$ & 40 & 38 \\
\hline IV Part skilled occupation & $2(5)$ & $2(5)$ & 17 & 15 \\
\hline V Unskilled & $0(0)$ & $1(2)$ & 5 & 5 \\
\hline $\begin{array}{l}\text { OTHER Students/forces/ } \\
\text { unemployed/those not } \\
\text { stating an occupation }\end{array}$ & $8(21)$ & $5(12)$ & 10 & 13 \\
\hline \multicolumn{5}{|l|}{ Schooling } \\
\hline Normal & $33(87)$ & $39(93)$ & & \\
\hline Special & $1(3)$ & $1(2)$ & & \\
\hline Preschool & $4(10)$ & $2(5)$ & & \\
\hline \multicolumn{5}{|l|}{ Hand dominance } \\
\hline Right & $32(84)$ & $36(86)$ & & \\
\hline Left & $6(16)$ & $6(14)$ & & \\
\hline
\end{tabular}

clinic if they had any problems or concerns regarding their child's fracture.

At the six-week follow-up, 38 patients (95\%) in the home group and $42(89 \%)$ in the hospital group were reviewed, and a radiograph of the fracture was obtained. Patients were questioned regarding their return to a full range of activities using the fractured wrist and a clinical assessment of function was made.

The parents were asked to complete a short questionnaire, based on visual analogue scales, to determine their level of satisfaction with the treatment which their child had received for the fracture and their preference for either hospital or home treatment if the need arose in the future. Parents and patients were asked to inform us of any specific problems which they had experienced regarding either treatment. Patients were discharged at this stage provided that there were no adverse clinical features.

A review of the patients who did not attend the six-week assessment, two in the home group and five in the hospital group, showed no difference in outcome from those who came for review.

Statistical analysis was performed using chi-squared tests for categorical data with Yates' continuity correction as appropriate. A Mann-Whitney test for independent variables was used to analyse movement of the wrist and patient satisfaction.

\section{Results}

Demographic data were compared for the hospital and home groups. Social class was determined by stated parental occupation using the Registrar General's classification system and compared with regional and national data to determine whether the study population was representative ${ }^{2}$ (Table I).

The patients were questioned regarding their initial injury. They were asked how and where they had sustained their fracture (home, school, or elsewhere). The severity of the injury was determined in terms of the initial pain experienced, swelling and deformity of the wrist; no difference was found between the two groups (Table II).

All the children attending the follow-up at six weeks were examined clinically. Swelling of the site of the fracture, deformity, tenderness and the range of wrist movement measured in degrees were recorded. No significant difference was found between the groups (Table II).

All patients in both groups were found to have no difficulty with writing, if relevant, or with activities of daily living. Only three patients $(8 \%)$ in the home group compared with seven $(17 \%)$ in the hospital group reported that they were still avoiding some hobbies; this difference (Table II) was not significant $(\mathrm{p}=0.40)$.

At the six-week review, radiographs were taken of 33 patients of whom 14 were in the home group and 19 in the hospital group. All showed satisfactory healing at the site of the fracture and none demonstrated increased deformity when compared with the initial films. Since all follow-up radiographs were satisfactory, the study team did not feel justified in continuing to perform this investigation in the remaining children involved in the study.

Analysis of parent and patient satisfaction with the treatment of the fracture, as determined by means of a linear visual analogue scale, showed that both groups appeared to be highly satisfied with the care that they had received 
Table II. Details of the initial injury and wrist function at six weeks, for the home (study) group versus the control (hospital) group

\begin{tabular}{|c|c|c|c|c|}
\hline & \multirow[b]{2}{*}{$\begin{array}{l}\text { Home } \\
\text { group }\end{array}$} & \multirow[b]{2}{*}{$\begin{array}{l}\text { Hospital } \\
\text { group }\end{array}$} & \multicolumn{2}{|l|}{ p value } \\
\hline & & & $\begin{array}{l}\text { Chi-squared } \\
\text { test }\end{array}$ & $\begin{array}{l}\text { Mann-Whitney } \\
\text { test }\end{array}$ \\
\hline \multicolumn{5}{|l|}{ Injury sustained } \\
\hline At home & 14 & 17 & 0.56 & \\
\hline At school & 15 & 12 & & \\
\hline Elsewhere & 9 & 13 & & \\
\hline \multicolumn{5}{|l|}{ Immediate pain } \\
\hline Severe & 29 & 34 & 0.87 & \\
\hline Mild/moderate & 9 & 8 & & \\
\hline \multicolumn{5}{|l|}{ Initial swelling } \\
\hline None/mild & 12 & 17 & 0.55 & \\
\hline Moderate/severe & 26 & 25 & & \\
\hline \multicolumn{5}{|l|}{ Initial deformity } \\
\hline Yes & 1 & 1 & 1.00 & \\
\hline No & 37 & 41 & & \\
\hline \multicolumn{5}{|l|}{ Swelling at 6 weeks } \\
\hline None & 37 & 42 & 0.96 & \\
\hline Mild & 1 & -- & & \\
\hline \multicolumn{5}{|l|}{ Tenderness at 6 weeks } \\
\hline None & 35 & 39 & 1.00 & \\
\hline Mild & 3 & 3 & & \\
\hline \multicolumn{5}{|l|}{ Deformity at 6 weeks } \\
\hline None & 38 (all patients) & 42 (all patients) & & \\
\hline \multicolumn{5}{|l|}{ Wrist movement* } \\
\hline Dorsiflexion & 0.9 & 0.4 & & 0.3 \\
\hline Palmar flexion & 0.8 & 0.5 & & 0.6 \\
\hline Radial deviation & 0.7 & 0.5 & & 0.9 \\
\hline Ulnar deviation & 0.3 & 0.2 & & 0.9 \\
\hline Pronation & 0.3 & 0.0 & & 0.3 \\
\hline Supination & 0.3 & 0.0 & & 0.3 \\
\hline Writing and activities of daily living & 38 (all patients) & 42 (all patients) & & \\
\hline \multicolumn{5}{|l|}{ Hobbies } \\
\hline Manages all & 35 & 35 & 0.40 & \\
\hline Avoids some & 3 & 7 & & \\
\hline
\end{tabular}

* mean as difference in degrees between the fractured side and the normal wrist

$(\mathrm{p}=0.43)$. Parents were also asked if they had experienced any problems in the care of their child's fracture. Only five parents $(13 \%)$ in the home group compared with $14(33 \%)$ in the hospital group stated that they had experienced such problems. Using the chi-squared test the $\mathrm{p}$ value for comparison of the groups was 0.04 , but with the continuity correction this significance was reduced to 0.06. All 14 parents in the hospital group who stated that they had experienced problems took the opportunity to expand on their difficulties, compared with only two of the five in the home group. This obvious difference adds weight to the possibility that a larger study group could have found a statistically significant difference between the groups in terms of stating that they had experienced problems related to the care of their child's fracture. Of the 47 in the hospital group, ten parents complained about hospital waiting times, five found it difficult to get time off work to attend hospital appointments, three had transport difficulties and two felt that hospital parking was inadequate. One parent, whose child had been randomised to the hospital group, removed an uncut backslab at home in order to avoid the loss of earnings which would have ensued from a hospital visit.

No parent in the home group had difficulties in removing their child's backslab, and none returned to the hospital for the removal. One parent in the home group stated that she was nervous about caring for her child's fracture and thus delayed removal of the backslab until six weeks after injury, but managed without difficulty to remove it at home. Of the two parents having problems in the home care group, one stated that they had wanted a spare bandage and the other that their child had removed the backslab before the given date.

The parents in both home and hospital groups stated that they were satisfied with the management of their child's fracture. When asked if they would choose to repeat the treatment given if in future there was a choice of either hospital or home removal, a highly significant difference was found between the two groups $(p<0.001)$. Those in the home group were much more likely to prefer the same treatment again compared with those in the hospital group (Fig. 1).

Of the patients asked if the backslab had remained 


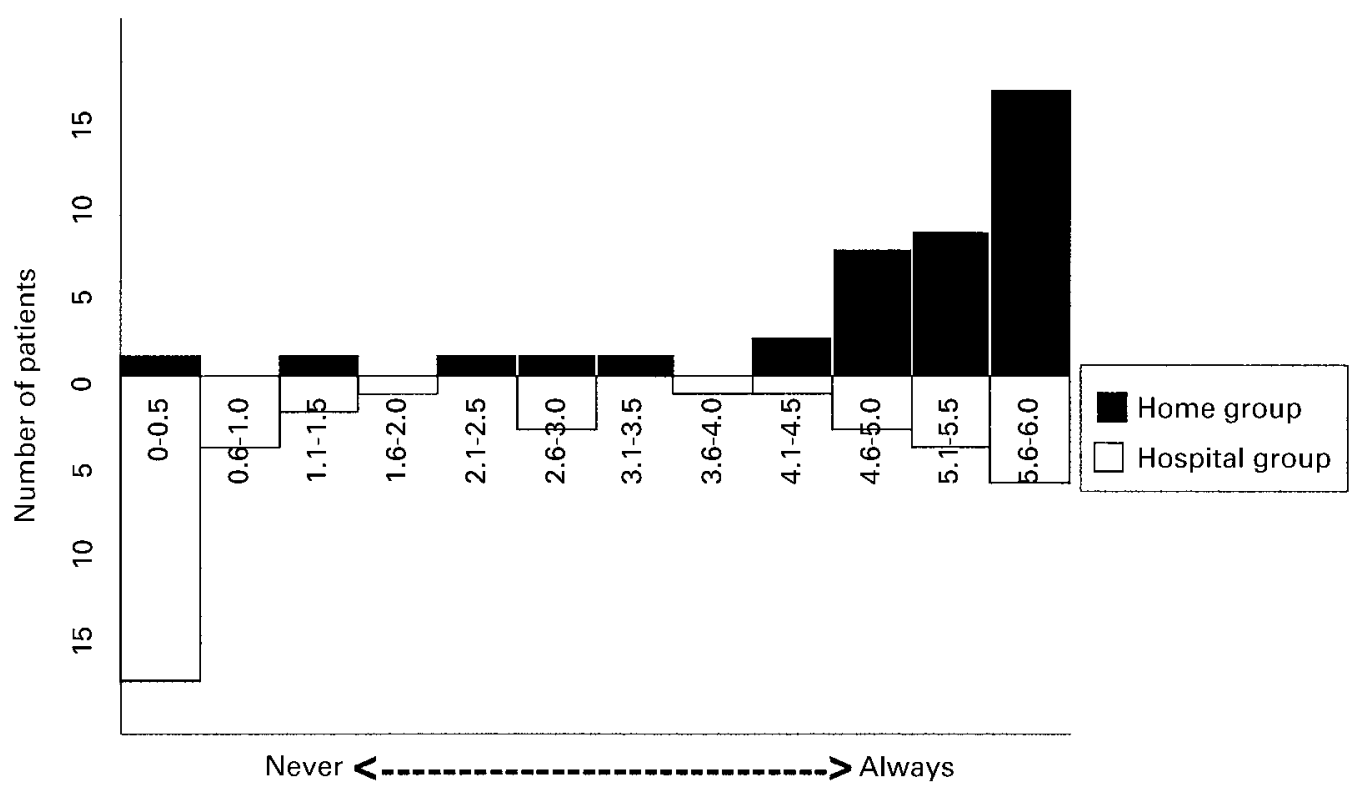

Fig. 1

Graph comparing groups on whether parents would choose the same treatment again. Number of patients: home group mean 4.99, SD 1.33, $\mathrm{n}=38$; hospital group mean 2.38, SD 2.38, $\mathrm{n}=42$.

supportive throughout the three-week period, four in the home group compared with two in the hospital group stated that it had become soft. This difference was not significant. In addition, seven parents in the home group compared with only one in the hospital group commented that they would have liked a spare bandage to enable them to care better for their child's backslab at home. This difference was thought to be related to the fact that the precut backslabs in the home group had an increased likelihood of becoming ragged or loose. No parent returned to the hospital because a backslab was loose, all managing to remedy the situation at home.

\section{Discussion}

Home management of buckle fractures has clear benefits for the patient's family as well as hospital staff, without shifting the responsibility for care of the fracture to the general practitioner. It would reduce the number of patients in the clinic, relieving pressure on medical and nursing staff, and parents would not have to take time off work. The frustrations of hospital waiting times and transport difficulties would be avoided, and the patients themselves would not miss school.

This strategy introduces the small additional cost of a crepe bandage required for rewrapping the predried, precut backslabs, as described. The financial impact on the UK hospital, if home management for this fracture were to be introduced, is small but the potential to decrease waiting times in the clinic is large.

Having determined the benefits of home management for these fractures for very little increased cost, the potential risks of this procedure need to be clearly defined. Clinical responsibility for the patient lies with medical staff If patients are not followed up there is an obvious concern that problems will be missed. Deformity should not occur in a true torus or buckle fracture since the tension side of the cortex remains intact. ${ }^{3,4}$ However, in a recent radiological study of undisplaced or minimally displaced fractures of the distal third of the radius, Schranz and Fagg 5 found that $7.1 \%$ of unicortical fractures with a dorsal buckle did displace in plaster. They did not conclude from these results that buckle fractures should be treated as potentially unstable, and repeat radiography was not advised. It was noted that any angulation was unlikely to cause functional disability. Our study has confirmed, as has been found elsewhere, that the clinical risks of managing a buckle fracture in which a below-elbow backslab is used are small. No child who had a radiograph taken in our study was found to have displacement of the fracture, and functional results in all patients were excellent.

There is a risk that parental anxiety regarding a child's fracture may be exacerbated by the responsibility of home management. Parents could have concerns regarding removal of the plaster and what to expect after. For these reasons, during this study, a clear explanation and demonstration of removal of the backslab were given. Parental concern about using scissors to remove a child's backslab was avoided by the use of precut and rewrapped backslabs. As has been shown, no parent involved in the study had any problem with its removal.

Information in the form of a booklet on fracture care could readily address most of the uncertainties experienced by parents, particularly regarding activities after the cast 
has been removed. Four parents with children in the home group stated that they would have liked further information in booklet form. It is vital that parents who are asked to remove their child's backslab at home do not feel that medical staff are abdicating responsibility for management of the fracture. Parents in our study were given full access to the fracture clinic and were advised both verbally and in writing to telephone or return to the clinic should they have any concerns regarding their child's fracture.

No benefits in any form have been recieved or will be received from a commercial party related directly or indirectly to the subject of this article.

\section{References}

1. Mbubaegbu CE, Munshi NI, Currie L. Audit of patient satisfaction with self-removable soft cast for greenstick fractures of the distal radius. J Clin Effect 1997;2:14-5.

2. Social classifications and coding methodology. Standard Occupational Classification. Vol. 3. Office of Population Censuses and Surveys. London: HMSO.

3. Hughston JC. Fractures of the forearm in children. J Bone Joint Surg [Am] 1962;44-A:1678.

4. O'Brien ET. Fractures of the hand and wrist region. In: Rockwood CA, Wilkins KE, King RE, eds. Fractures in children. Vol. 3. Philadelphia: Lippincott, 229.

5. Schranz PJ, Fagg PS. Undisplaced fractures of the distal third of the radius in children: an innocent fracture? Injury 1992;23:165-7. 